\title{
CLASSIFICATION OF METEORITES BY PETROPHYSICAL METHODS
}

\author{
ILMO T. KUKKONEN and LAURI J. PESONEN
}

KUKKONEN, ILMO T. and PESONEN, LAURI J. 1983: Classification of meteorites by petrophysical methods. Bull. Geol. Soc. Finland $55,2,157-177$.

The low field magnetic susceptibility, natural remanent magnetization (NRM) and bulk density were measured for 75 meteorite samples from 54 meteorites ranging from achondrites through chondrites and stony-irons to irons. The results show distinct relations between susceptibility and NRM and between susceptibility and bulk density. The susceptibility and intensity of NRM increase from achondrites to irons as a function of increasing metallic Ni-Fe content. Moreover, subclasses of meteorites appear as different groupings in the petrophysical relation diagrams. The susceptibility density diagram in particular offers a rapid method for identifying a meteorite group and subgroup. The petrophysical classification method was successfully applied to previously published petrophysical data from the meteorite collections of the U.S.S.R. When meteorites are compared with terrestrial basic igneous rocks, the petrophysical properties of the terrestrial rocks (peridotites, pyroxenites, gabbros, diorites and diabases) are seen to fall outside the area of achondrites in the susceptibility - NRM diagram. Thus it is possible, in principle, to distinguish achondrites from terrestrial rocks by petrophysical measurements.

Two factors considerably reduce the apparent susceptibility values measured. First, the shape demagnetization effect becomes very important in the case of stony-irons and irons rich in metallic $\mathrm{Ni}-\mathrm{Fe}$. Second, the apparent susceptibility of stony-irons and irons is reduced owing to the high value of the electrical conductivity, because the measurements were done with an alternating current bridge. These effects can be corrected by giving the sample a regular shape and by applying a frequency dependent correction factor for the susceptibility values.

The nature of NRM was studied by applying a storage test, which revealed that the NRM is very liable to changes due to spurious laboratory fields. Alternating field demagnetization of the Haverö achondrite (ureilite) and the Orgueil carbonaceous chondrite (CI1) suggest that these meteorites carry mainly a soft and semistable NRM component, although a weak and harder - perhaps extraterrestrial - component may be present.

Key words: meteorites, petrophysics, magnetic susceptibility, remanent magnetization, density.

Ilmo T. Kukkonen, Geological Survey of Finland, Exploration Department, Kivimiehentie 1, SF-02150 Espoo 15, Finland.

Lauri J. Pesonen, Geological Survey of Finland, Geophysics Department, Kivimiehentie 1, SF-02150 Espoo 15, Finland. 


\section{Introduction}

Several papers have been published during the past two decades on the magnetic properties of meteorites. Particular attention has been paid to the alternating field $(\mathrm{AF})$ demagnetization characteristics of NRM (natural remanent magnetization) and the thermomagnetic properties of meteorites (e.g. Stacey and Lovering 1961; Lovering and Parry 1962; Banerjee and Hargraves 1971, 1972; Butler 1972; Larson et al. 1974; Watson et al. 1975; Herndon et al. 1976; Brecher and Fuhrman 1979; Nagata 1979).

The main purpose of these studies was to investigate whether the NRM, ubiquitously present in every meteorite sample, is of extraterrestrial origin and to establish the factors which affect the NRM of meteorites during and since the early history of the solar system. The studies reveal that in most of the meteorites investigated, the NRM, or at least a component of it, is of extraterrestrial origin (Herndon and Rowe 1974; Nagata 1979).

In most studies the measurements concentrated on NRM. Only a few papers (e.g. Stacey and Lovering 1961; Weaving 1962; Nagata 1979) yield information on other magnetic properties, such as low field susceptibility and magnetic hysteresis data. Investigations on the petrophysical systematics and possible correlations between magnetic and other petrophysical properties (e.g. density and electrical conductivity) have been very few (see Wasson 1974, for a summary).

Herndon et al. (1972) and Sonett (1978) reviewed the work done in the U.S.S.R. by Gus'kova (1965), Gus'kova and Pochtarev (1967) and Gorshkov et al. (1972). According to Herndon et al. (1972), the following relations exist between the magnetic properties and the meteorite class.

Both susceptibility and NRM increase from achondrites to chondrites through stony-irons to irons, principally as a result of an increase in the content of metallic nickel-iron. "The magnetic susceptibility of chondrites is crudely related to the Ni-Fe content, with the L- and H-group chondrites forming two clearly defined groups.» The correlations do not exist only between the main groups of chondrites but also between the petrologic subgroups (Van Schmus and Wood, 1967) within the main groups (Herndon et al. 1972, p. 265). For instance, the intensity of NRM and susceptibility increase from $\mathrm{L} 3$ to $\mathrm{L} 6$ and from $\mathrm{H} 4$ to $\mathrm{H} 6$, respectively (Herndon et al. 1972, Table 2, p. 282).

Basing their observations upon NRM alone, Brecher and Ranganayaki (1975) obtained similar results. They widened the scope to include LL and E chondrites, showing that the intensity of NRM increases from $\mathrm{LL}$ to $\mathrm{L}$ through $\mathrm{H}$ to $\mathrm{E}$ chondrites together with an increase in the Ni-Fe content.

Nagata (1979) has shown that stony meteorites can be classified according to their saturation magnetization properties. In Nagata's diagram (the relative amount of Ni-poor kamacite magnetization vs. saturation magnetization), C, LL, L, H and $\mathrm{E}$ chondrites as well as achondrites appear as independent groups. Sugiura (1977) observed that the coercive force of chondrites increases in the sequence E-H-L-LL-C.

We have investigated the feasibility of using petrophysical properties such as NRM, weak field susceptibility and bulk density as an aid to the classification of meteorites. For this purpose, the petrophysical properties of 75 meteorite samples from 54 meteorites (previously classified by petrologic-chemical methods) were measured. Using this material we present several types of petrophysical relation diagrams which may be used to classify 
meteorites fairly rapidly. The validity of the petrophysical classification methods was first verified by reclassifying the petrophysical meteorite data from the U.S.S.R. reported in the review by Herndon et al. (1972). We studied in detail the effect of sample shape demagnetization on the measurement results of the susceptibility of one iron meteorite (Mungindi, IIIC). The effect of electrical conductivity of the meteorite samples on the low field susceptibility measured by the A.C. bridge method will also be discussed. We present AF-demagnetization results of two meteorite samples Haverö (ureilite) and Orgueil (CI 1 chondrite) - in order to study the characteristics of NRM in these meteorites. Finally, we give the findings of a storage test carried out to investigate the type and origin of the NRM of ten meteorites.

\section{Limitations of the petrophysical methods}

To investigate the prefall history of the NRM of meteorites, one must first eliminate the possibility that the NRM is produced viscously or isothermally under the influence of the Earth's magnetic field or by spurious fields in the laboratory. This can be done by standard paleomagnetic experiments (demagnetization, storage tests, etc.) (e.g. McElhinny 1973).

The fusion crust of meteorites, acquired through the atmospheric fall, is associated typically with relatively strong magnetic moments induced by the Earth's field. The nature of this remanence is isothermal (IRM) or thermal (TRM) (Stacey and Banerjee 1974). The thickness of the crust is at most only a few $\mathrm{mm}$, and it must be removed before the NRM of the interior of the meteorite can be studied (Weaving 1962).

Unlike the fusion crust, the interior of a meteorite is not heated to a high temperature during the atmospheric fall (Lovering et al. 1960). It is, however, warmed from a temperature of about $-270^{\circ} \mathrm{C}$ in interplanetary space to the ambient temperature on the Earth's surface. Although theoretically the warming up does not have a serious effect on the magnetic grains carrying the remanence, it has not been investigated in detail. The effect of the slight shock on landing on the surface of the Earth and the subsequent surface weathering also considerably alter the original petrophysical properties of meteorites.

Meteorite samples are generally preserved in museums and collections, where they are continuously under the influence of the Earth's magnetic field and other spurious a.c. and d.c. fields. This may result in viscous (VRM) and isothermal (IRM) effects in the NRM of the samples.

To overcome these problems, each meteorite sample should be subjected to detailed alternating field and thermal demagnetization studies combined with hysteresis and thermomagnetic studies. These studies, however, cause irrevocable changes in the natural remanent magnetization and in the chemical-mineralogic composition of meteorites and are therefore not always permitted.

\section{Laboratory measurements}

The 75 meteorite samples from 54 different meteorites were taken from four Finnish meteorite collections (see Appendix). Most of the samples were fractions of meteorites, often with sawed planes; some had the shape of a thin plate. The dimensions of the samples varied from about $10 \mathrm{~cm}$ to less than $1 \mathrm{~cm}$. The mass of the samples ranged from $0.2 \mathrm{~g}$ to $263 \mathrm{~g}$ and the volume from $1 \mathrm{~cm}^{3}$ to $312 \mathrm{~cm}^{3}$. A clearly visible fusion crust was present in at least 18 samples as noted in the Appendix. 
It was to be expected that the diversity of shape, the presence of a fusion crust and the varying degree of weathering in the samples would cause considerable scatter in the measured values of susceptibility, remanence and density. It was not possible, however, to remove the fusion crust of the museum samples nor to form all the samples into the same shape. The effect of the shape of the samples on the petrophysical determinations will be discussed on p. 168 .

The natural remanent magnetization (NRM), magnetic low field susceptibility $(\chi)$ and bulk density (@) of the samples were measured in the Petrophysical Laboratory of the Geological Survey of Finland.

The NRM was measured with a fluxgatetype system ("Oerstedt-meter»), which permits the measurement of samples of diverse shape and size. The accuracy is about $\pm 0.01 \mathrm{~A} / \mathrm{m}$ (Puranen 1978).

The magnetic susceptibility was measured with an A.C. susceptibility bridge designed by Puranen and Puranen (1977). The accuracy is about $\pm 10^{-6}$ SI-units and the operating frequency was $1 \mathrm{kHz}$.

The bulk density was measured using the air - water weighing method. The density measurements are accurate within $0.01 \mathrm{~g} / \mathrm{cm}^{3}$. In some samples, particularly in chondrites, the density measurements were hindered by the porosity and the small sample size. The values of the volume therefore had to be either approximated or then the density was taken from published values.

A paleomagnetic storage test was performed on ten meteorite samples in order to study the influence of the Earth's magnetic field on the NRM. In this test the samples were stored inside a wooden hut outside the main building of the Geological Survey, where they were affected only by the Earth's magnetic field and not by any stray fields in the main building. The samples were always stored in the same position with respect to the Earth's field. The original orientation of the samples was arbitrary. During the test the intensity and direction of the NRM of the samples were measured about once a week over a period of three months. The measurements were, however, done inside the main building in a typical laboratory environment.

The results of the laboratory measurements for each sample are given in the Appendix. The magnetic susceptibility is expressed as a mass susceptibility in SI units:

$$
\chi=-\frac{\chi_{\text {SI }}}{\varrho} \quad\left(\mathrm{m}^{3} \mathrm{~kg}^{-1}\right)
$$

where $\chi_{\overline{S I}}$ is the measured volume susceptibility (dimensionless and $\varrho$ is the bulk density $\left(\mathrm{kgm}^{-3}\right)$.

NRM $(=\mathrm{M})$ is expressed as the intensity of natural remanent magnetization per unit mass:

$$
\mathrm{M}=-\frac{\mathrm{M}_{\mathrm{SI}}}{\varrho} \quad\left(\mathrm{Am}^{2} \mathrm{~kg}^{-1}\right)
$$

where $\mathrm{M}_{\mathrm{SI}}$ is the measured intensity of NRM $\left(\mathrm{Am}^{-1}\right)$.

\section{Results}

The results are summarized in Table 1 following the classification by Wasson (1974).

The susceptibility and the intensity of the NRM increase from achondrites through chondrites and stony-irons to irons, principally with regard to the increasing content of metallic Ni-Fe. There is considerable overlap between the groups, but the trend is nevertheless clear.

Within the chondrites, the susceptibility and the NRM intensity increase systematically from LL to $\mathrm{E}$ chondrites in accordance with the increasing content of metallic Ni-Fe. This trend, based on weak field sus- 
Table 1. Classification of meteorites using magnetic susceptibility and intensity of NRM. Values in parentheses represent results corrected for shape demagnetization according to Osborn's (1945) method.

\begin{tabular}{|c|c|c|c|c|c|c|}
\hline CLASS & $\mathrm{Fe} \%$ & $\mathrm{n}$ & $\bar{\chi}$ & $\chi_{\min }, \chi_{\max }$ & $\mathrm{M}$ & $\mathrm{M}_{\min }, \mathrm{M}_{\max }$ \\
\hline \multicolumn{7}{|c|}{ Irons } \\
\hline I & & $3(3)$ & $\begin{array}{c}6610 \\
(17960)\end{array}$ & $\begin{array}{c}3960-9770 \\
(14675-23310)\end{array}$ & $\begin{array}{c}81 \\
(425)\end{array}$ & $\begin{array}{c}63-106 \\
(230-700)\end{array}$ \\
\hline II & & $1(1)$ & $\begin{array}{c}6360 \\
(19350)\end{array}$ & $\stackrel{-}{(-)}$ & $\begin{array}{r}330 \\
1953\end{array}$ & $\stackrel{-}{(-)}$ \\
\hline III & & $4(4)$ & $\begin{array}{c}17850 \\
(60350)\end{array}$ & $\begin{array}{l}10040-34180 \\
(16460-131470)\end{array}$ & $\begin{array}{c}2760 \\
(29000)\end{array}$ & $\begin{array}{c}540-6330 \\
(1570-61000)\end{array}$ \\
\hline IV & & $1(1)$ & $\begin{array}{l}13600 \\
(21650)\end{array}$ & $(-)$ & $\begin{array}{c}3410 \\
(22650)\end{array}$ & - \\
\hline \multicolumn{7}{|c|}{ Stony-Irons } \\
\hline Pallasites & $28-88$ & $5(5)$ & $\begin{array}{c}6590 \\
(17610)\end{array}$ & $\begin{array}{l}2480-9270 \\
(2700-30180)\end{array}$ & $\begin{array}{c}1780 \\
(6120)\end{array}$ & $\begin{array}{c}190-4290 \\
(1350-16840)\end{array}$ \\
\hline Mesosiderites & $30-55$ & $3(3)$ & $\begin{array}{c}7600 \\
(14010)\end{array}$ & $\begin{array}{c}5550-8970 \\
(10750-20430)\end{array}$ & $\begin{array}{l}1150 \\
(3930)\end{array}$ & $\begin{array}{c}55-2350 \\
(160-9010)\end{array}$ \\
\hline \multicolumn{7}{|c|}{ Chondrites } \\
\hline $\mathrm{E}$ & $19-25$ & $2(2)$ & $\begin{array}{c}3760 \\
(3890)\end{array}$ & $\begin{array}{c}3600-3730 \\
(3770-4060)\end{array}$ & $\begin{array}{l}1400 \\
(2060)\end{array}$ & $\begin{array}{c}1190-1610 \\
(1770-2350)\end{array}$ \\
\hline $\mathrm{H}$ & $15-19$ & $11(13)$ & $\begin{array}{l}1400 \\
(1930)\end{array}$ & $\begin{array}{c}370-3260 \\
(390-4200)\end{array}$ & $\begin{array}{c}750 \\
(1360)\end{array}$ & $\begin{array}{c}30-3430 \\
(40-9220)\end{array}$ \\
\hline $\mathrm{L}$ & $4-9$ & $12(22)$ & $\begin{array}{c}590 \\
(610)\end{array}$ & $\begin{array}{l}290-820 \\
(290-860)\end{array}$ & $\begin{array}{c}150 \\
(150)\end{array}$ & $\begin{array}{c}10-540 \\
(10-600)\end{array}$ \\
\hline LL & $0.3-3$ & $4(6)$ & $\begin{array}{l}250 \\
(250)\end{array}$ & $\begin{array}{l}20-650 \\
(20-680)\end{array}$ & $\begin{array}{c}10 \\
(10)\end{array}$ & $\begin{array}{c}4-20 \\
(4-20)\end{array}$ \\
\hline $\mathrm{C}$ & $0-8$ & $2(6)$ & $\begin{array}{c}413 \\
(442)\end{array}$ & $\begin{array}{c}230-610 \\
(230-650)\end{array}$ & $\begin{array}{c}15 \\
(16)\end{array}$ & $\begin{array}{l}2-45 \\
(2-50)\end{array}$ \\
\hline \multicolumn{7}{|c|}{ Achondrites } \\
\hline Ureilites & $0.3-6$ & $2(3)$ & $\begin{array}{c}930 \\
(1030)\end{array}$ & $\begin{array}{c}610-1250 \\
(630-1430)\end{array}$ & $\begin{array}{l}1010 \\
(1360)\end{array}$ & $\begin{array}{l}10-2000 \\
(10-2720)\end{array}$ \\
\hline Aubrites & ca. 1 & 1(1) & $\begin{array}{c}40 \\
(40)\end{array}$ & $\begin{array}{l}- \\
-\end{array}$ & $\begin{array}{c}6 \\
(6)\end{array}$ & - \\
\hline Diogenites & $<1$ & $1(1)$ & $\begin{array}{l}50 \\
(50)\end{array}$ & - & $\begin{array}{c}4 \\
(4)\end{array}$ & - \\
\hline Eucrites & $<0.1$ & $3(3)$ & $\begin{array}{l}6 \\
(6)\end{array}$ & $\begin{array}{c}4-8 \\
(4-8)\end{array}$ & $\begin{array}{c}4 \\
(4)\end{array}$ & $\begin{array}{c}4-5 \\
(4-5)\end{array}$ \\
\hline
\end{tabular}

$\begin{array}{ll}\text { CLASS } & - \text { Meteorite classification according to Wasson (1974) } \\ \mathrm{Fe} \% & - \text { Average contents of metallic Fe according to Wasson (1974) } \\ \mathrm{n} & - \text { Number of different meteorites examined. Number of individual samples is given } \\ & \text { in parentheses } \\ \chi, \chi_{\min }, \chi_{\max } & -\begin{array}{l}\text { Arithmetic mean of susceptibility, minimum and maximum values of susceptibility } \\ \end{array} \\ \mathrm{M}, \mathrm{M}_{\min }, \mathrm{M}_{\max }- & \text { Arithmetic mean of NRM, minimum and maximum values of } \mathrm{NRM}\left(10^{-5} \mathrm{Am}^{2} \mathrm{~kg}^{-1}\right)\end{array}$

ceptibility data, is very similar to that observed in hysteresis measurements (saturation magnetization) (Nagata 1979). However, the susceptibilities reveal slightly more overlap between the subclasses than the saturation magnetization data (by Nagata). The reason for this is that the weak fields susceptibility is more sensitive to variations in 
grain size, structure of the grains and impurities than are the saturation magnetization data (Stacey and Banerjee 1974).

Carbonaceous chondrites (C) are magnetically similar to $\mathrm{LL}$ and certain $\mathrm{L}$ and $\mathrm{H}$ chondrites. The susceptibility and NRM values of $\mathrm{C}$ chondrites are, however, generally lower than those of $\mathrm{L}$ and $\mathrm{H}$ chondrites. Besides differing $\mathrm{Ni}-\mathrm{Fe}$ contents, this may reflect the variability in the magnetic phases of different chondrite classes. For instance, in ordinary chondrites ( $\mathrm{L}$ and $\mathrm{H}$ ) the magnetic phases are mainly kamacite with minor taenite and pyrrhotite (Stacey and Lovering 1961). In C1 and C2 carbonaceous chondrites the NRM is carried by submicroscopic magnetite or a thermally unstable phase that resembles troilite in thermomagnetic analysis.
This unstable ferro-oxysulphide phase oxidizes to magnetite during heating. In some $\mathrm{C} 3$ and $\mathrm{C} 4$ carbonaceous chondrites Ni-poor kamacite has been observed together with magnetite and the ferro-oxysulphide phase (Larson et al. 1974; Watson et al. 1975; Herndon et al. 1976).

Susceptibility and NRM intensity are generally lowest in achondrites (Table 1). However, the subclass of ureilites is clearly different from other achondrite subclasses in its higher susceptibility and NRM values. The ureilites in the U.S.S.R. data also show exceptionally high values of susceptibility and NRM (Herndon et al. 1972). This is a consequence of the considerably higher metallic Ni-Fe content of ureilites than of other achondrite subclasses (Wasson 1974).
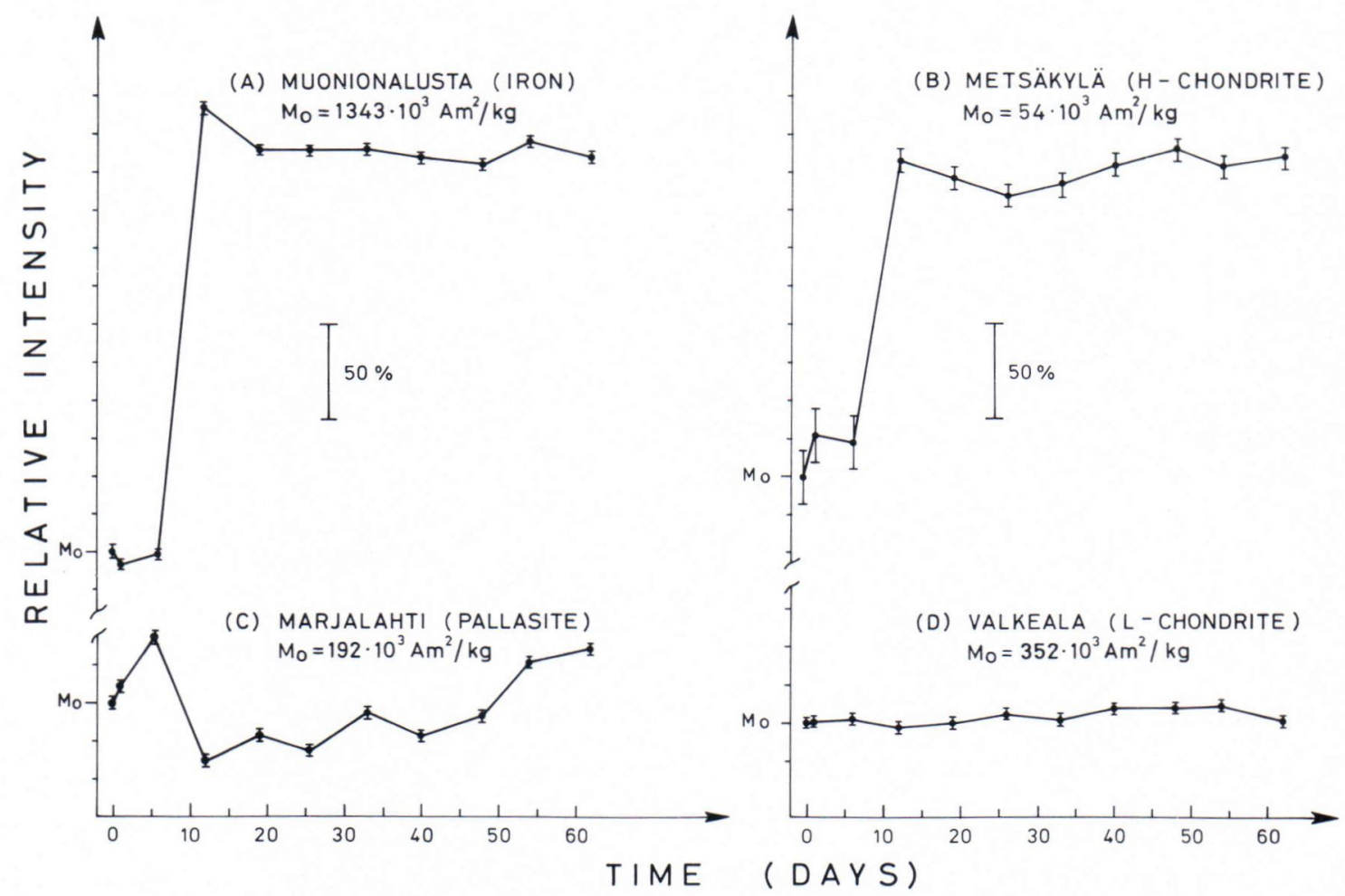

Fig. 1. Typical changes in the intensity of NRM during the storage test. Relative intensities of NRM are expressed in percentage of $M_{0}$, the original value of NRM intensity. The error bars indicate the smallest intensity change to be observed with the apparatus used. 


\section{Nature of NRM}

Examples of the paleomagnetic storage test results are given in figures 1 and 2 . If the changes in NRM directions were viscous in nature, the direction of the NRM could be expected to show a swing towards the direction of the Earth's magnetic field during the storage test. Some of the samples did
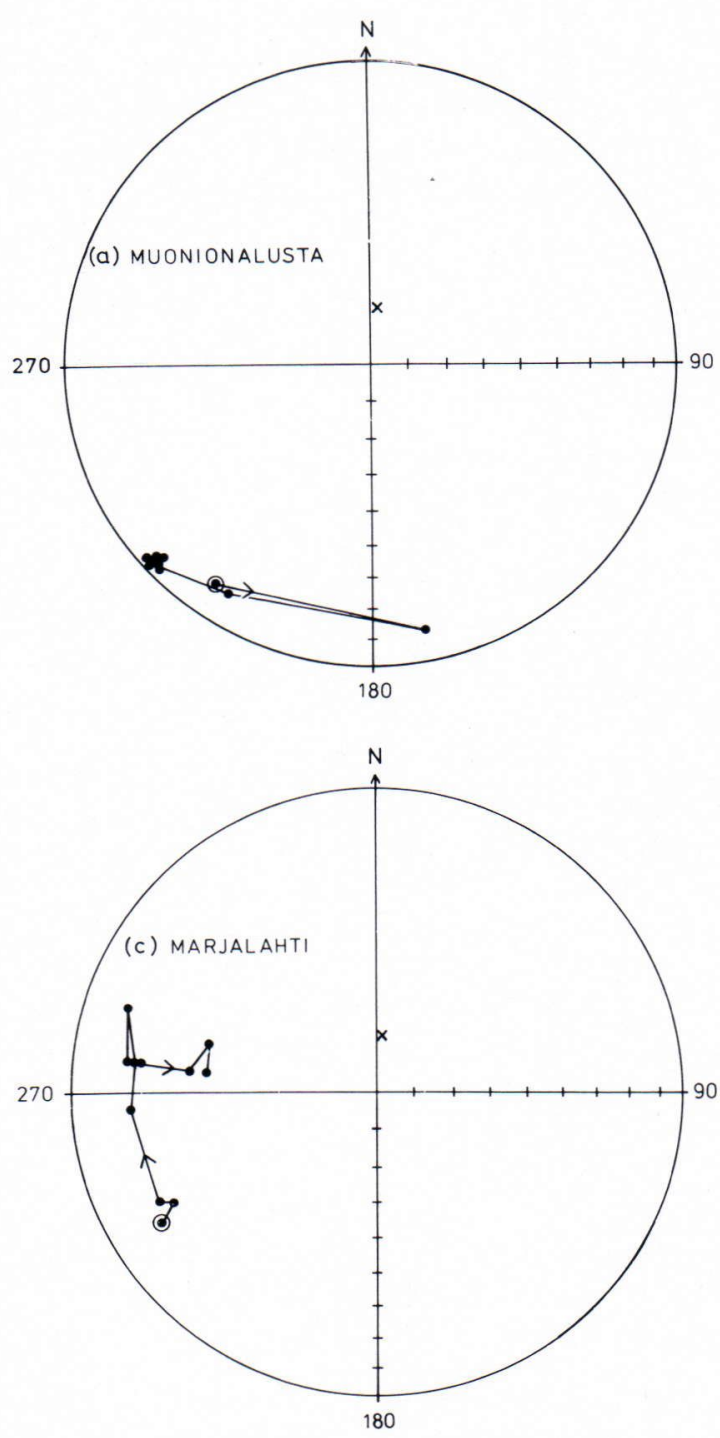

indeed reveal this kind of behaviour (e.g. Metsäkylä (H4 chondrite) and Marjalahti (pallasite), Figs. 1 and 2). In others the direction of remanence was either stable (e.g. Valkeala (L6 chondrite), Fig. 2) or more or less random (e.g. Muonionalusta (IVA iron), Fig. 1). The intensity of the NRM in one specimen (Stannern, eucrite) was too low to be definitely observable in this test.
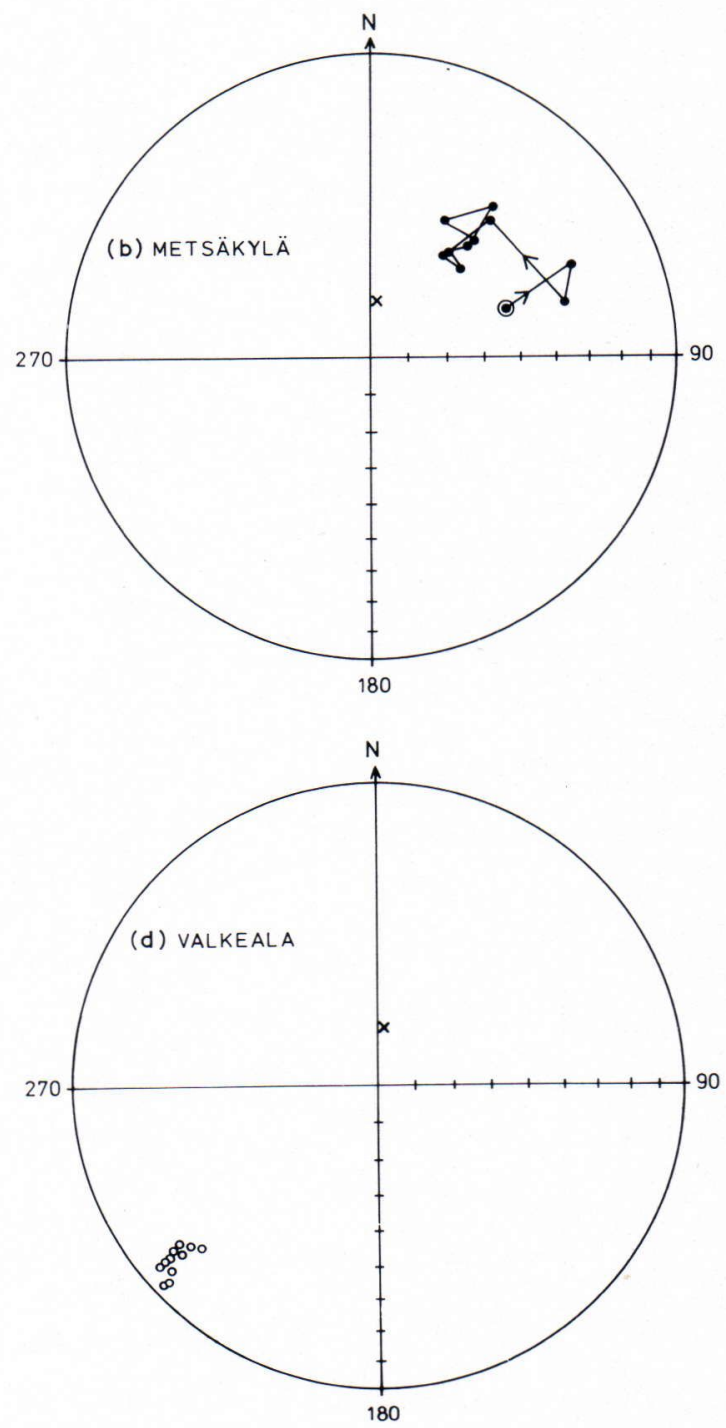

Fig. 2. Directional changes during storage test. Equal area stereonets with closed (open) symbols denoting downward (upward) inclinations. The original direction of NRM is shown with a double circle and is arbitrary with respect to figure coordinates. The direction of the Earth's geomagnetic field is indicated by a cross. 
The changes in the intensity of NRM during the storage test were highly variable. Some of the samples show similar intensity changes as a function of time (e.g. Muonionalusta (IVA iron), Marjalahti (pallasite) and Metsäkylä (H4 chondrite), Fig. 1) with a sharp increase in intensity between days 6 and 11 . The rapid changes in intensity correlate crudely with changes in the direction of the NRM (Fig. 2).

The reason for the observed sudden changes in the direction and intensity of NRM is unknown, but it is most probably a result of spurious disturbing fields in the laboratory environment. These changes cannot be explained by any effects of the Earth's static field.

It is also possible that the viscous changes take place much faster than can be observed in days and weeks. Gorshkov et al. (1975) observed viscous changes taking place in ten minutes in samples from Sikhote-Alin (IIB iron).

The shape of the sample appears to be an important factor for the direction of the NRM. All the samples with a platelike shape had a NRM vector directed essentially along the plane of the sawed plate. This is

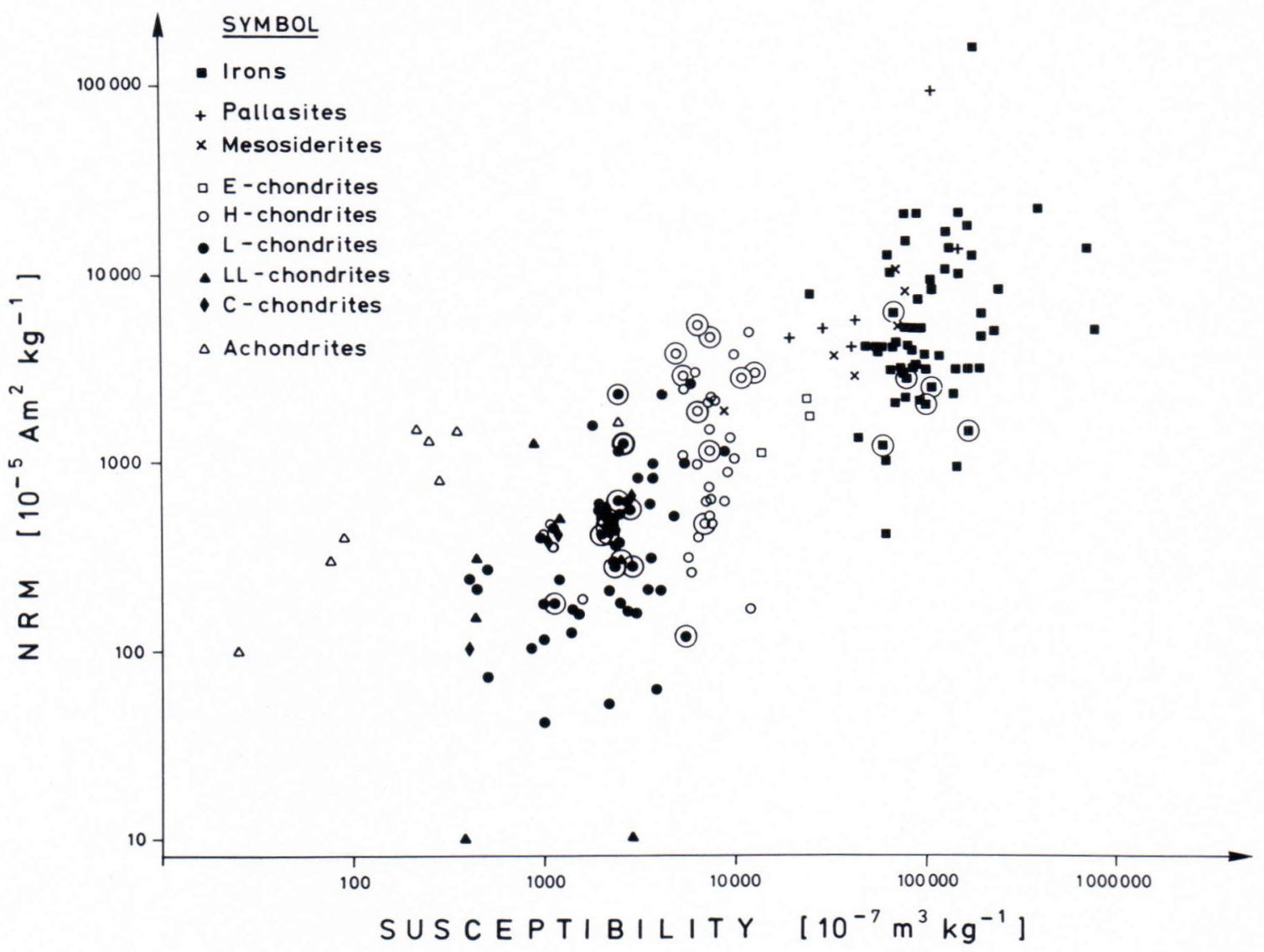

Fig. 3. Test of the petrophysical classification method. NRM is plotted against susceptibility (both per unit mass). The data from the U.S.S.R. meteorite collections are the same as used by Herndon et al. (1972) except that they are recalculated into SI units. The results with an extra circle around the symbol are listed in Herndon et al. (1972) without chemical classification, which in the present study is taken from Hey (1966) and Hutchison et al. (1977). The magnetic classification is in good agreement with the chemicalpetrological classification. 
a consequence of the shape demagnetization phenomena in the plate-like samples and will be discussed in more detail on p. 168 .

\section{Petrophysical relations}

Various petrophysical relations were examined from the data listed in the Appendix. The results are given in Figures 4-6. When more than one specimen of a meteorite was available, the values of each specimen were not plotted independently. Instead, the (logarithmic) mean values for each meteorite were used.

From the standpoint of classification, the petrophysical method was tested using the
U.S.S.R. data listed by Herndon et al. (1972). The results of the test were promising, and they are summarized in Figure 3.

Our susceptibility $(\chi)$ and NRM $(M)$ data appear to be approximately related in the log-log plot (Fig. 4). The relationship is obvious and different meteorite classes are readily distinguished. There is considerable scatter, especially in the NRM data, which is to be expected from the storage test results (see above). The linear regression line (loglog) from the data set yields

$$
\log \mathrm{M}=0.83 \log \chi-0.43
$$

with a correlation coefficient of 0.74 .

The relation between bulk density and susceptibility is given in Figure 5. Achondri-

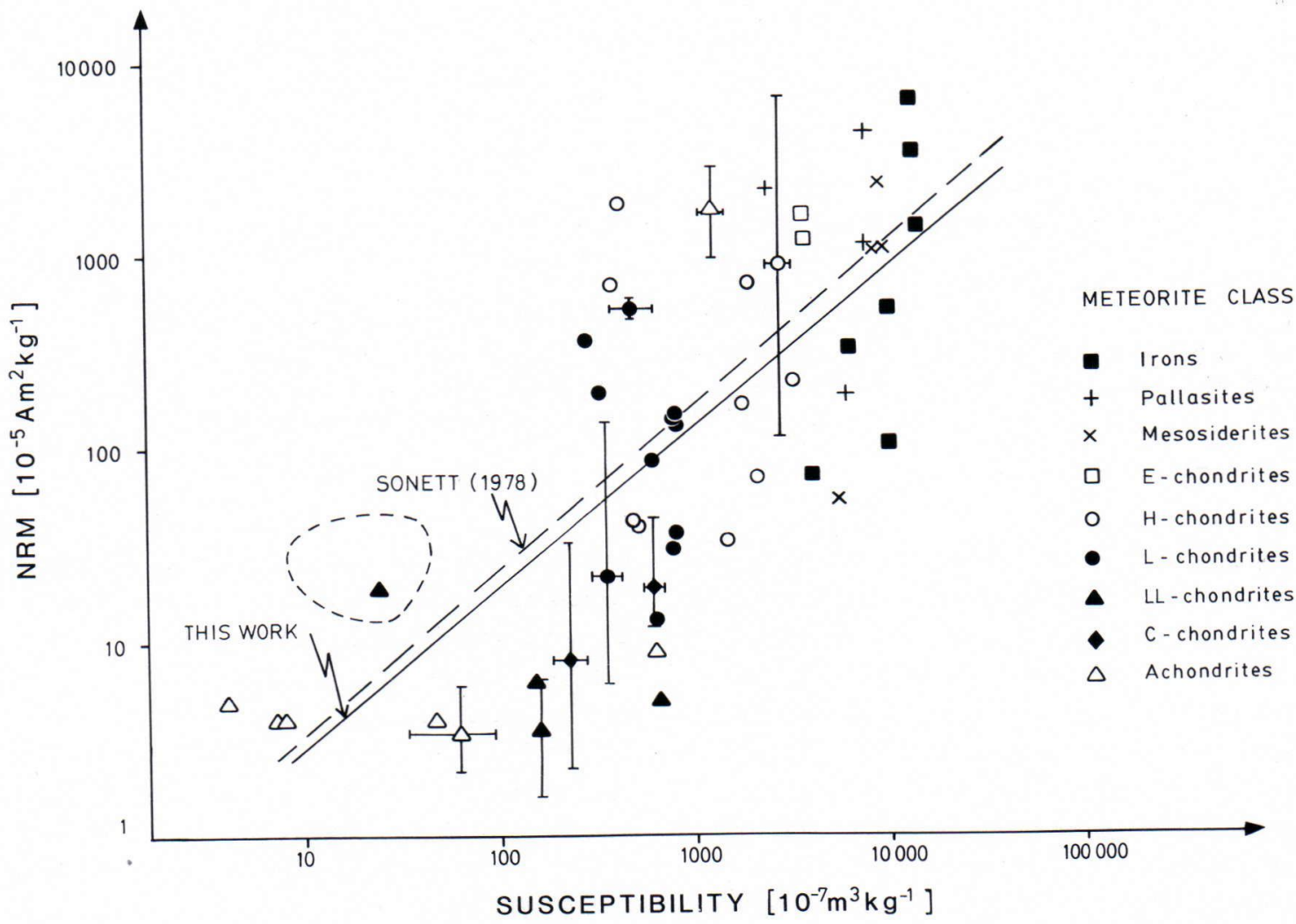

Fig. 4. The relation between the susceptibility and NRM of the meteorites investigated. Samples from 51 different meteorites. The error bars indicate the upper or lower limits of the NRM and susceptibility values for different samples of the same meteorite. The straight line is the best least square fit through all the data points. The broken line is taken from similar work by Sonett (1978). The closed dashed line gives the area of the most common terrestrial igneous rocks. See text for further details. 


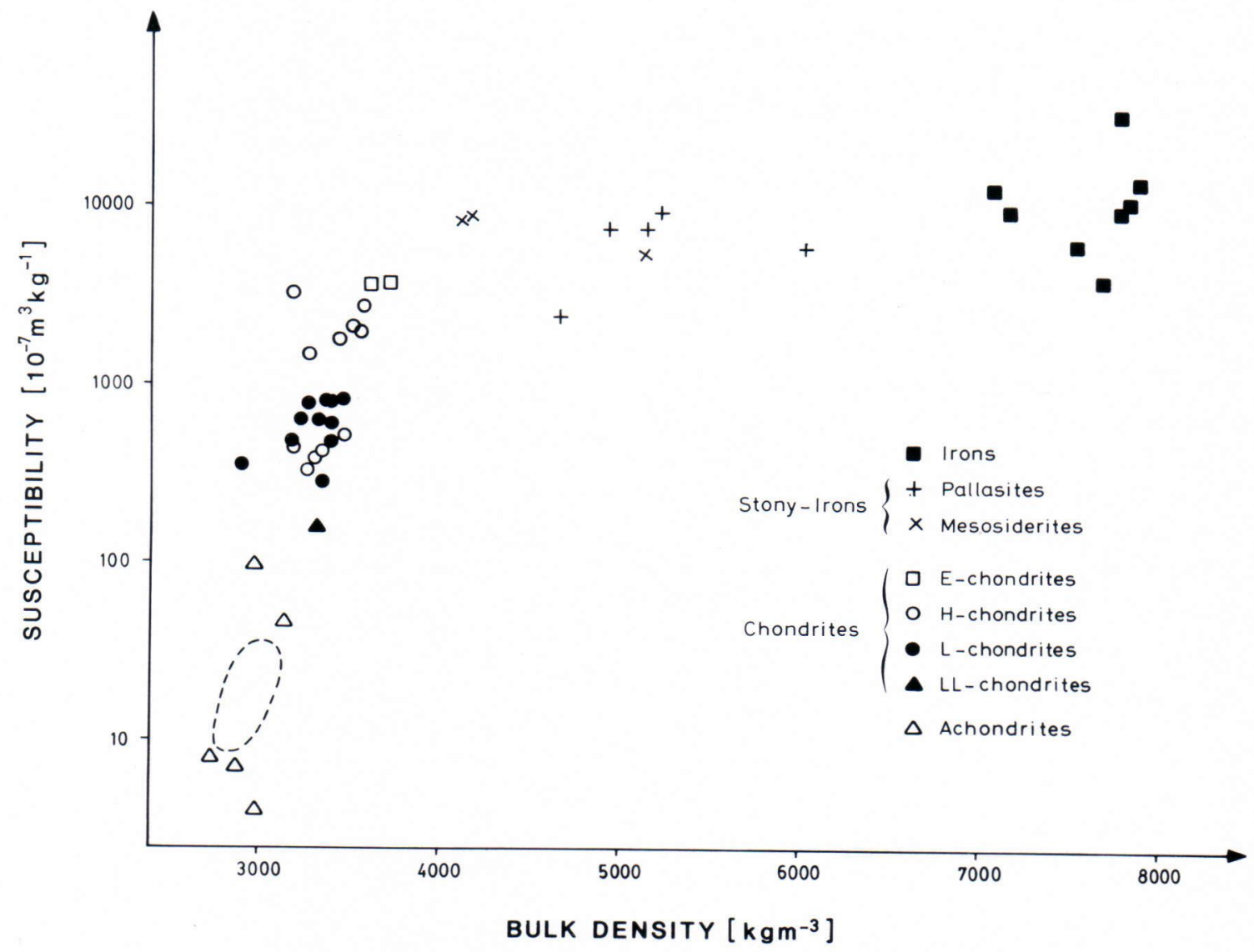

Fig. 5. The relation between the susceptibility and bulk density. Only data (samples from 46 different meteorites) from which the density was measured are included. The closed dashed line gives the area of the most common terrestrial igneous rocks. See text for further details.

tes and chondrites appear to form a linear relationship in which each chondrite subclass. is distinguished. Stony-irons and irons form another linear relationship, the slope of which is strongly depressed from that for achondrites and chondrites. The reason for this depression is discussed on p. 168.

Achondrites and different chondrite subclasses are distinguished as individual groups, although some overlap takes place. The same applies to stony-irons and irons.

For comparison, the average susceptibility, density and NRM intensity data of igneous terrestrial rocks (peridotites, pyroxenites, gabbros, diorites and diabases) of the Precambrian bedrock of Finland (Risto Puranen 1983, personal communication) are shown in Figures 4 and 5. In the susceptibility density diagram (Fig. 5) terrestrial rocks fall inside the achondrite field, but in the succeptibility - NRM diagram (Fig. 4) they fall clearly above the achondrite field with only one LL chondrite inside the terrestrial rock area. Thus it is possible, in principle, to distinguish achondrites from terrestrial rocks by petrophysical measurements.

The relation between the content of metallic Ni-Fe and susceptibility is given 
in Figure 6. The Ni-Fe contents were collected from Hey (1966), Wiik (1969), Hutchison et al. (1977) and Wasson (1974). There is considerable scatter in these values, but a clear positive correlation is evident between susceptibility and the content of metallic $\mathrm{Ni}$ Fe. The cause of the scatter may be in the Ni-Fe contents. The values, although for the same meteorites, do not necessarily correspond to the pieces of specimens measured in our laboratory.

The Koenigsberger ratios (Q) of meteorites were also examined, but no correlation was found between these ratios and other petrophysical quantities. A modified Koenigsberger ratio (e.g. after $5 \mathrm{mT}$ AF-demagnetization) could be a better expression because the relative effect of spurious laboratory fields or other secondary components would be eliminated (Pesonen 1973).

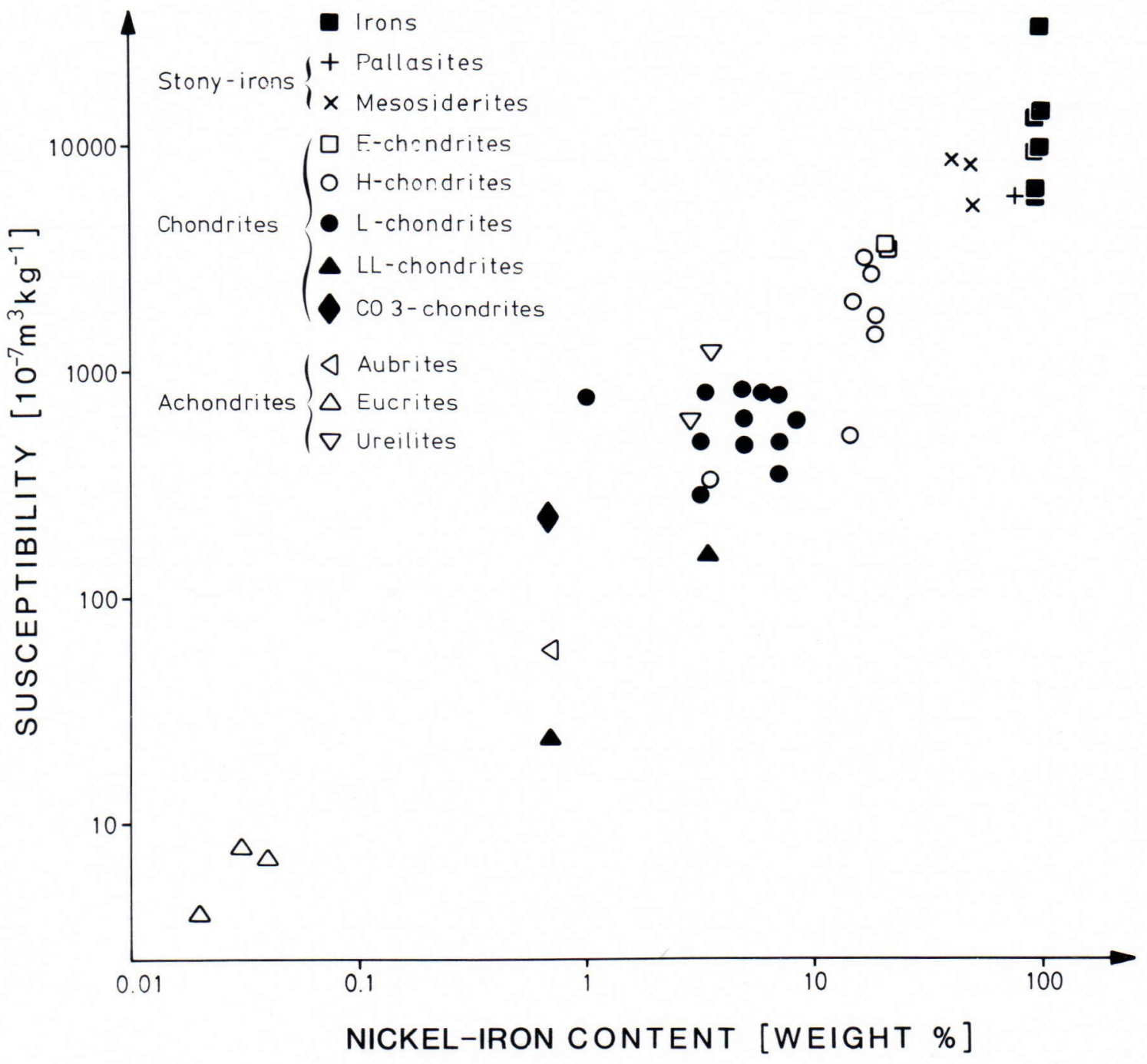

Fig. 6. The relation between susceptibility and metallic nickel-iron content. Samples from 42 different meteorites. Only samples with known Ni-Fe content given either by Hey (1966), Wiik (1969), Hutchison et al. (1977) or Wasson (1974) are included. 


\section{Effects of demagnetization on susceptibility}

The measured susceptibility values of stony-irons and irons are strongly depressed in the susceptibility - bulk density plot (Fig. 5), partly because of the demagnetization phenomenon (related to the shape of the specimens) and partly because of the electric conductivity effect in the measurement of susceptibility with an AC-bridge (operating frequency, $1000 \mathrm{~Hz}$ ). Let us first discuss the shape demagnetization effect.

The measured apparent volume susceptibility is expressed by the equation (Stacey and Banerjee 1974):

$$
\chi_{\mathrm{a}}=\frac{\underline{\chi}_{\mathrm{t}}}{1+\mathrm{N} \chi_{\mathrm{t}}},
$$

where $\mathrm{N}$ is the demagnetization factor, and $\chi_{t}$ and $\chi_{a}$ are the "true" and "apparent" volume susceptibilities, respectively. The demagnetization factor is determined from the shape of the specimen with respect to the direction of the applied magnetic field.

The corresponding correction for the measured intensity of NRM is

$$
M_{\mathrm{a}}=\frac{\mathrm{M}_{\mathrm{t}}}{1+\mathrm{N} \chi_{\mathrm{t}}}
$$

where $\mathrm{M}_{\mathrm{t}}$ and $\mathrm{M}_{-\mathrm{a}}$ are the »true» and »apparent» values of NRM, respectively.

There are several methods for determining $\mathrm{N}$ by approximating the shape of the specimen with different kinds of ellipsoids (Osborn 1945; Stacey and Banerjee 1974), prisms (Joseph and Schlömann 1965; Joseph 1967; Sharma 1968) or cylinders (Noltimier 1971).

Many specimens in this study can be crudely approximated with a general prism, a thin rectangular plate or an ellipsoid. It is thus possible, in principle, to calculate

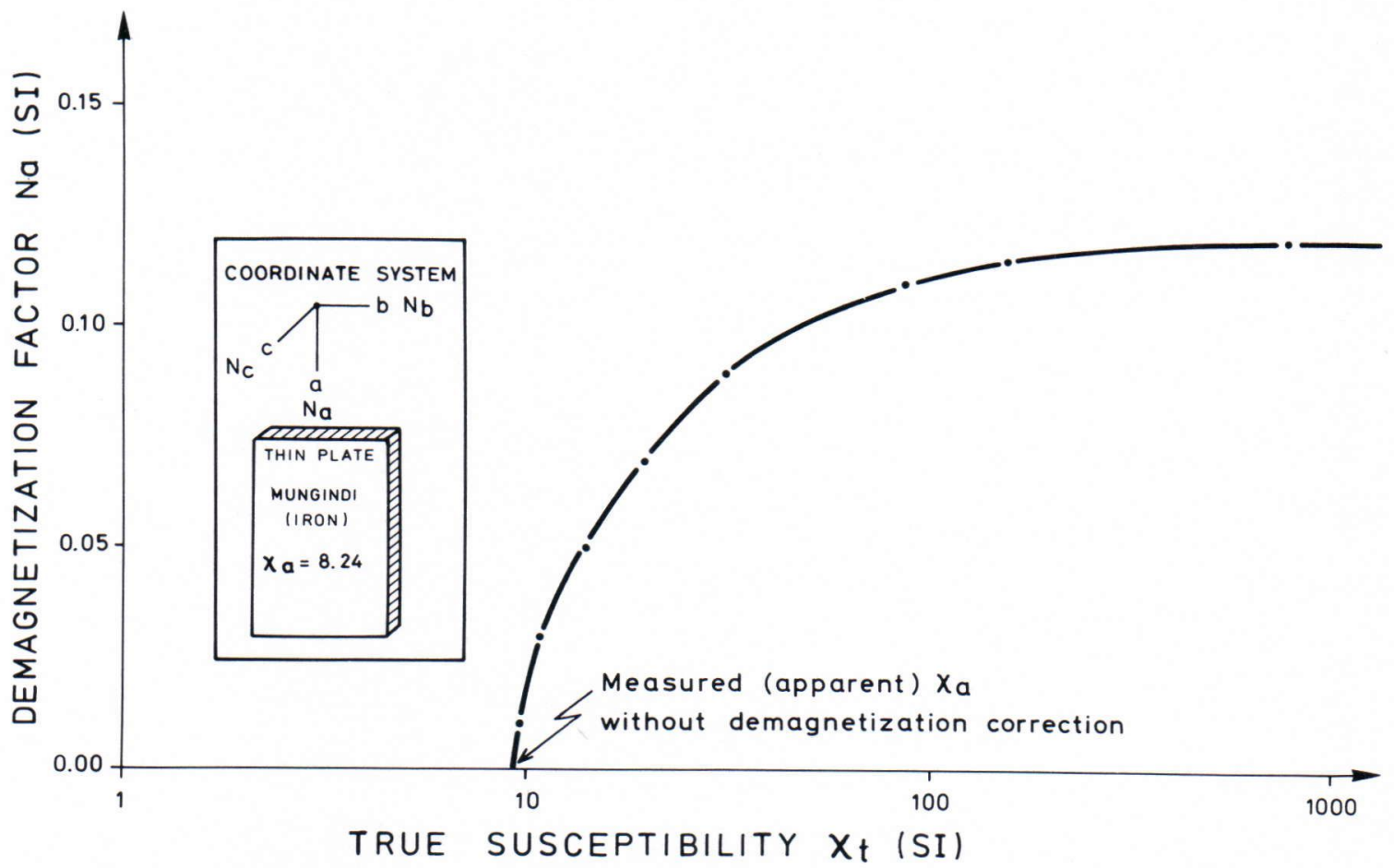

Fig. 7. The effect of the demagnetization factor $N$ on the estimation of the true susceptibility $\chi_{t}$ of the Mungindi iron meteorite with the shape of thin plate measuring $6.0 \times 4.5 \times 0.5 \mathrm{~cm}$. The apparent measured susceptibility is $\chi_{\mathrm{a}}=8.24 \mathrm{SI}$ along the a-direction. 
the demagnetization factor $\mathrm{N}$ for each specimen from its shape.

In practice, however, the case is not straightforward. In Figure 7 the true susceptibility $\chi_{t}$ from equation (4) is plotted against the demagnetization factor $\mathrm{N}_{\mathrm{a}}^{-}$for the Mungindi IIIC iron meteorite as an example. It is obvious that rather small variations in approximation of the demagnetization factor result in considerable changes in demagnetization-corrected susceptibility values. This can be readily verified because the samples are never ideal in shape and the value of $\mathrm{Na}$ typically has a range of inaccuracy of $\pm 20 \%$.

Furthermore, the demagnetization factor is not a constant depending solely on specimen shape but a function of susceptibility (Eskola et al. 1977). In Figure 8, the apparent susceptibility $\chi_{a}$ of a cube specimen is plotted against the true susceptibility $\chi_{t}$ with the reciprocal of $\mathrm{N}$ as a parameter.

With increasing values of $\chi_{t}$ the values of $\chi_{a}$ reach an upper limit of approximately $3.55 \mathrm{SI}$ units, which is also equal to the value of $1 / \mathrm{N}$.

Therefore, we must conclude that high values of $\chi_{a}$ reflect only the demagnetization effects, which cannot be eliminated without careful shaping of the specimen. When the susceptibility is below 1 SI (i.e. chondrites and achondrites), however, the demagnetization effects are virtually negligible.

This is observed in Table 1, where demagnetication-corrected values of susceptibility and NRM are given together with measured values. The demagnetization factors were approximated for each specimen by Osborns's (1945) method.

\section{The conductivity effect}

The susceptibility was measured by the AC-bridge method (Puranen and Puranen, 1977) at an operating frequency of $1000 \mathrm{~Hz}$. For ordinary rock samples with low con- ductivity the measured susceptibility is not seriously affected by the induction (eddy current) effect (Brown 1979). For highly conductive iron meteorites, however, the conductivity of the sample will considerably reduce the value of apparent susceptibility, even at a frequency of $1000 \mathrm{~Hz}$ (Poikonen 1980).

A method is therefore needed to correct the measured susceptibility caused by the induction effect. This is particularly important when susceptibility values measured with an AC-bridge are compared with values measured by the zero frequency method using an astatic magnetometer.

Poikonen (1980) has investigated the effect of conductivity on susceptibility applied to the GSF AC-bridge apparatus. The problem is complex (see e.g. Brown 1979) and can be mathematically treated only in the case of simple geometries, e.g. a sphere in a homogeneous field. In the present study only very crude estimates of the effect can be made, as the value of conductivity is unknown and the sample is not spherical.

Poikonen (1980) has calculated theoretical correction curves for the measured susceptibility of a sphere with a free parameter called the response parameter $\alpha$

$$
\alpha=\mu_{\mathrm{o}} \omega \sigma \mathrm{r}^{2},
$$

where $\mu_{0}^{-}$is the permeability of the vacuum $\left(=4 \pi \cdot 10^{-7} \mathrm{Hm}^{-1}\right), \omega$ is the angular frequency $(=2 \pi \mathrm{f}), \quad \sigma$ is conductivity $\left(\mathrm{Sm}^{-1}\right)$ and $\mathrm{r}$ is the radius $(\mathrm{m})$ of the sphere.

The Mungindi (IIIC iron) sample was studied in detail to decide whether it was possible to remove the effects of demagnetization and conductivity from the susceptibility values measured.

The sample is a non-regular plate measuring approximately $6.0 \times 4.5 \times 0.5 \mathrm{~cm}$. A small cube, each side measuring $0.44 \mathrm{~cm}$, was sawed off the main specimen and prepared for reference. This cube and the 


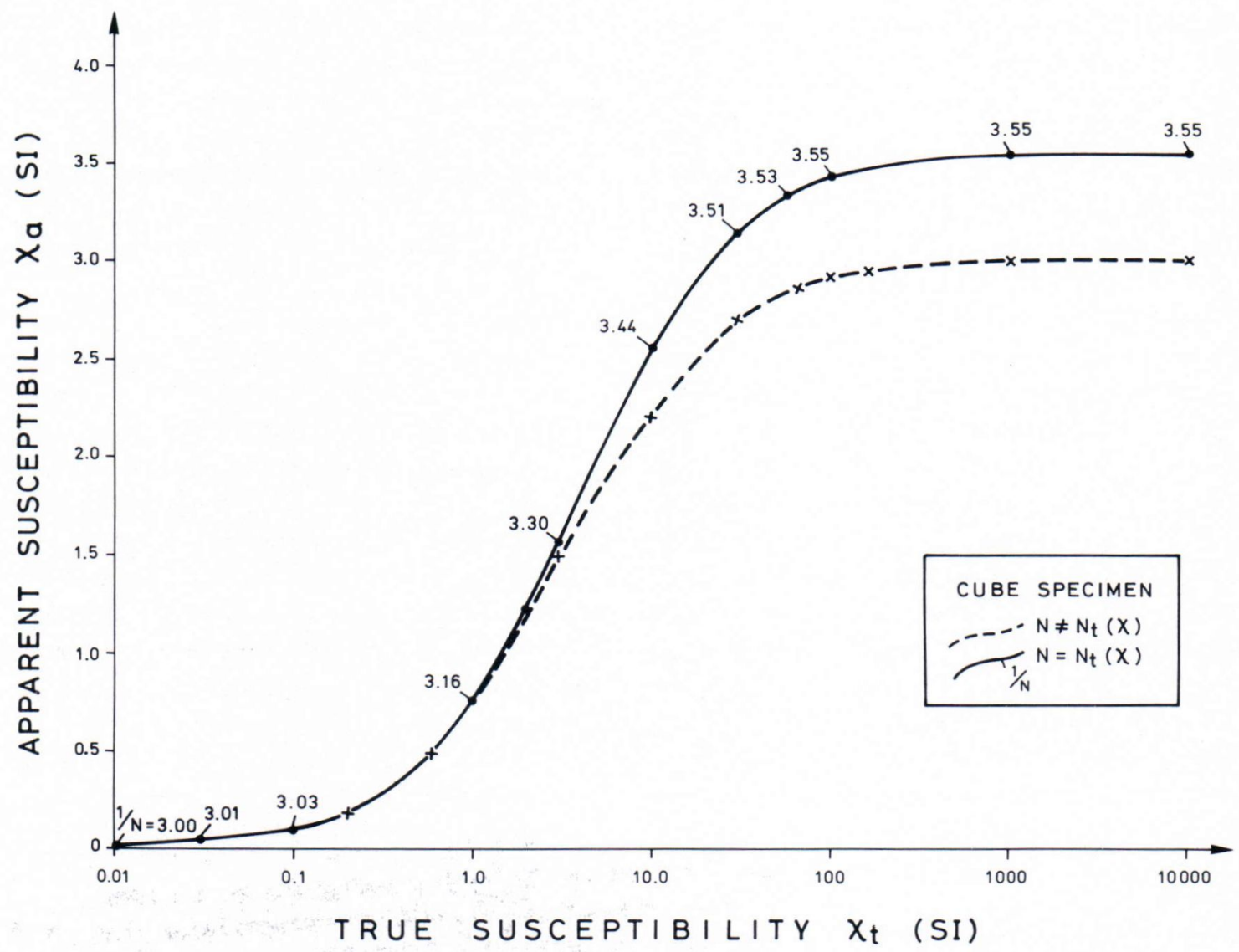

Fig. 8. The relation between apparent susceptibility and true (demagnetization corrected) susceptibility in the case of a cube specimen. The broken line $\mathrm{N}$ does not depend on $\chi_{t}$ (i.e. $1 / \mathrm{N}=$ constant $=3.0$ ) whereas the solid line depends on $\chi_{t}$. When $\chi_{t}>10(\mathrm{SI})$, the measured susceptibility approaches asymptotically a constant value equal to $1 / \mathrm{N}$.

original sample were carefully measured with the AC bridge in three orthogonal directions, $a, b$ and $c$, determined from the sample shape. Direction a represents the longest dimension and $\mathrm{c}$ the shortest.

The demagnetization factors for the cube specimen were determined as in Eskola et al. (1977) taking into account the functional dependence of $\mathrm{N}$ of $\chi_{\mathrm{t}}$. Demagnetization factors for the plate-like Mungindi sample were approximated according to Osborn's (1945) ellipsoid method and Joseph's (1967) general prism method.
The conductivity effect was taken into account as follows. Poikonen's (1980) correction curves were calculated for spherical bodies, and they apply only up to true susceptibility values of about 10 SI. We first extrapolated the curves up to about $40 \mathrm{SI}$ using standard curve-fitting techniques (Pesonen and Kukkonen 1983). The platelike samples were then treated as " analogous spheres" in such a way that the area perpendicular to the measurement direction corresponded to the surface area of a spherical specimen. The radii of the "analogous 
spheres» were then solved and used in the correction curves.

The results of the demagnetization and conductivity corrections of the Mungindi susceptibility values are summarized in Table 2. The results of a static (i.e. zero frequency) susceptibility measurement conducted by the Technical Research Center of Finland (Väinö Kelhä 1982, written communication) are also included. For comparison, the shape demagnetization effect was corrected according to both Osborn's (1945) ellipsoid and Joseph's (1967) prism methods.

In Table 2, the conductivity of the specimen was taken as $1 \cdot 10^{7} \mathrm{Sm}^{-1}$, the value for pure iron (Knowlton 1949). The presence of nickel in iron, however, decreases conductivity. For example, the amount of c. $3 \% \mathrm{Ni}$ alloyed in iron would decrease the conductivity of the alloy from $1 \cdot 10^{7} \mathrm{Sm}^{-1}$ to $1 \cdot 10^{6} \mathrm{Sm}^{-1}$ (Knowlton 1949 , p. 229), resulting in a decrease of about $20-50 \%$ in the conductivity-corrected susceptibility values in Table 2 (Pesonen and Kukkonen 1983).
Therefore, the conductivity correction presented here is no more than an estimation of the magnitude of the correction.

Nevertheless, it seems possible to calculate true susceptibility values from apparent values measured with an AC bridge, but the method involves detailed and complicated correction procedures.

\section{AF-demagnetization results}

The AF-demagnetizations of the Haverö ureilite and the Orqueil carbonaceous chondrite (CI1) are presented in Figure 9. The results suggest that these meteorites carry mainly a soft and semistable NRM, although a weak and harder - perhaps extraterrestrial - component may be present. Banerjee and Hargraves $(1971,1972)$ observed similar AF characteristics for the Orgueil chondrite and interpreted their findings to indicate the presence of a stable extraterrestrial remanence component.

Table 2. Shape demagnetization and electrical conductivity effects on Mungindi III C iron. Cube and plate-like samples.

\begin{tabular}{|c|c|c|c|c|c|c|c|c|c|c|}
\hline \multirow{2}{*}{$\begin{array}{l}\text { Direction } \\
\text { of measure- } \\
\text { ment } \\
(\mathrm{a}>\mathrm{b}>\mathrm{c})\end{array}$} & \multicolumn{9}{|c|}{ AC - BRIDGE $(1 \mathrm{kHz})$} & \multirow{2}{*}{\begin{tabular}{|c} 
STATIC MEA \\
SUREMENT $\left.{ }^{1}\right)$ \\
PLATE $\left.^{3}\right)$ \\
$\chi^{\prime \prime}\left(=\chi_{\mathrm{a}}\right)$
\end{tabular}} \\
\hline & \multicolumn{3}{|c|}{$\mathrm{CUBE}^{2}$ ) } & $x_{a}-$ & $\begin{array}{l}\text { Osborn } \\
\chi^{\prime} \rightarrow\end{array}$ & & $\chi_{\mathrm{a}}$ & $\begin{array}{l}\text { oseph) } \\
\chi^{\prime} \rightarrow\end{array}$ & $-\chi^{\prime \prime}$ & \\
\hline $\begin{array}{l}\mathrm{a} \\
\mathrm{b} \\
\mathrm{c}\end{array}$ & $\begin{array}{l}3.19 \\
3.25 \\
2.93\end{array}$ & 30 & 45 & $\begin{array}{l}8.24 \\
7.40 \\
0.63\end{array}$ & $\begin{array}{r}14 \\
18 \\
1\end{array}$ & $\begin{array}{l}36 \\
56 \\
24\end{array}$ & $\begin{array}{l}8.24 \\
7.40 \\
0.63\end{array}$ & $\begin{array}{r}26 \\
45 \\
1\end{array}$ & $\begin{array}{r}53 \\
\geq 56 \\
25\end{array}$ & $\begin{array}{l}51 \\
37 \\
24 \\
\end{array}$ \\
\hline Mean & & & 45 & & & 39 & & & 39 & 37 \\
\hline
\end{tabular}

$\chi_{\mathrm{a}} \quad$ measured apparent susceptibility (SI)

$\chi$ demagnetization corrected susceptibility (SI)

$\chi$, demagnetization and conductivity corrected susceptibility (SI)

1) conducted by the Technical Research Center of Finland (Väinö Kelhä 1982, written communication)

2) cube dimensions $0.44 \times 0.44 \times 0.44 \mathrm{~cm}$. See text.

3) plate dimensions (approx.) $6.0 \times 4.5 \times 0.5 \mathrm{~cm}$. See text. 


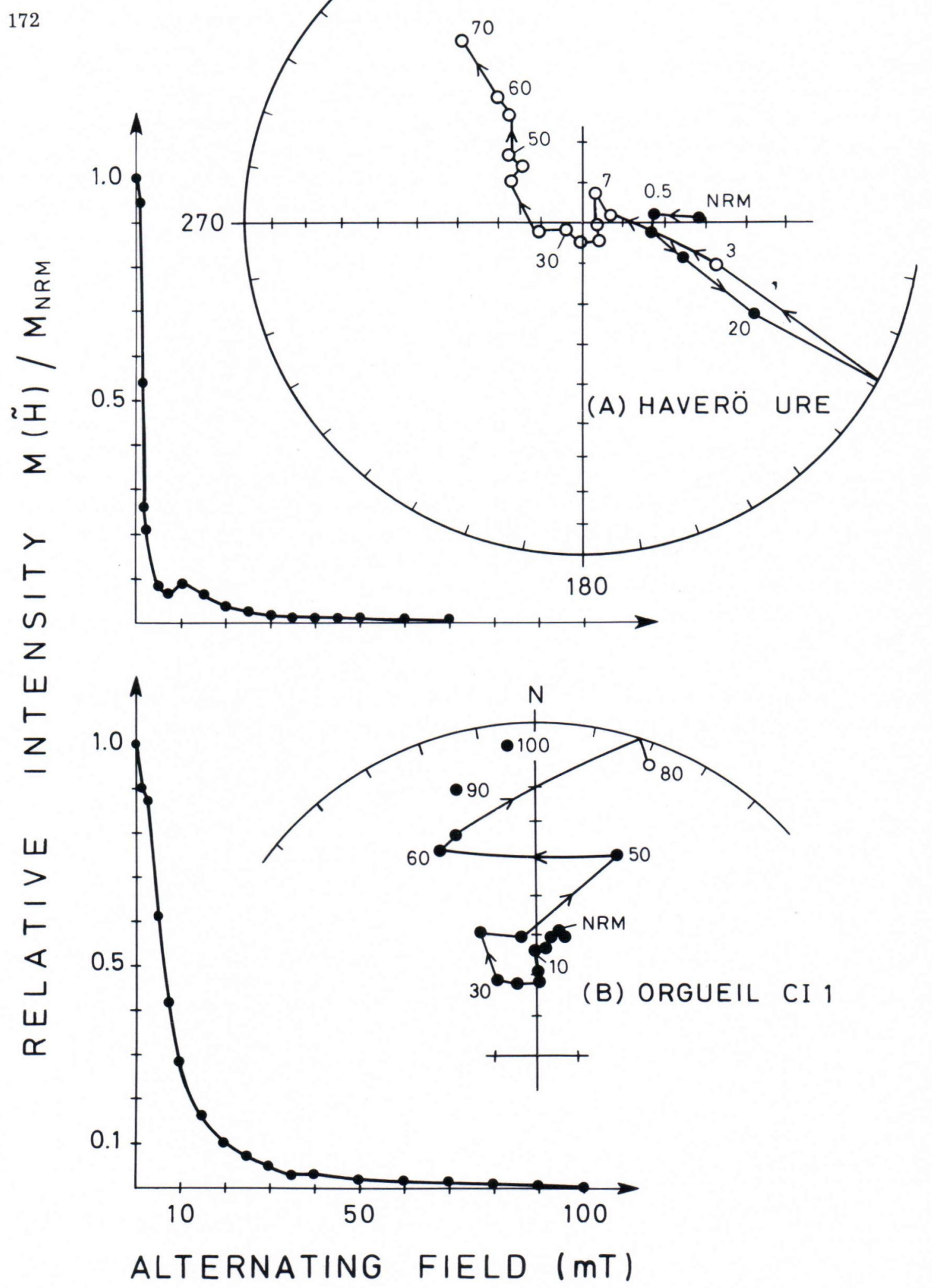

Fig. 9. Alternating field demagnetization data on (A) Haverö achondrite (ureilite), (B) Orqueil carbonaceous chondrite (CI1). Left: normalized relative intensity of NRM as a function of peak alternating field up to 70 or $100 \mathrm{mT}$. Right: directions of NRM, numbers indicate the a.f. values in milliteslas. Equal area stereonets with closed (open) symbols denoting positive (negative) inclinations. The direction of NRM before demagnetization is arbitrarily chosen. 


\section{Discussion and conclusions}

When considering the classification of meteorites by petrophysical methods, one must remember that these observations cannot replace classification by petrological and chemical methods, because the petrophysical properties are strictly governed by ferromagnetic minerals, that is Ni-Fe alloys. The petrophysical method, however, might be valuable in meteoritics when used in combination with other methods.

The following conclusions can be drawn. Certain relations seem to exist between different petrophysical properties of meteorites. By applying these relations, useful classification schemes can be obtained. The relation between susceptibility and bulk density in particular (Fig. 5) appears to be very useful because these properties are closely related to the content of metallic $\mathrm{Ni}-\mathrm{Fe}$ in meteorites and in contrast to the NRM, do not show radical changes with time. The measurements of bulk density and susceptibility do not cause any harmful mineralogical or chemical changes in the meteorite samples.

Because of the overlap in measured values between different classes, it would certainly be difficult to apply a petrophysical property alone in classification. Especially NRM seems to be unsuitable for classification purposes because of its scattered nature. A low field AF-demagnetization (fields below, say, $5 \mathrm{mT}$ ) before measuring NRM would perhaps reduce the scatter of NRM intensity data produced by spurious laboratory fields.
The phenomena of demagnetization and conductivity discussed above do not in any way hinder use of the susceptibility - bulk density plot for classification purposes, as long as each sample is always measured in the same way. In interlaboratory comparisons, on the other hand, the demagnetization and conductivity corrections would have to be taken into account. These corrections, however, are necessary only for stonyirons and irons; chondrites and achondrites can be classified fairly reliably without them.

The metallic nickel-iron content of a meteorite can probably be estimated from its petrophysical properties once a reliable calibration curve has been constructed between the susceptibility and Ni-Fe content.

Finally, the susceptibility - NRM diagram can be used to distinguish achondrites from common terrestrial igneous rocks.

Acknowledgements. We are grateful to Professor B. Wiik and Dr. M. Lehtinen (Department of Geology and Mineralogy, University of Helsinki, the Mineralogical Museum), B. Söderholm (Department of Economic Geology, Helsinki University of Technology) and C. Kortman (Mineralogical Museum of the Geological Survey of Finland), who supplied us with the meteorite samples. Our thanks are further due to R. Puranen for his advice on use of the apparatus of the Petrophysics Laboratory of the Geological Survey, to Professor L. Eskola, A. Poikonen and T. Tervo, who gave helpful comments regarding the problems of shape demagnetization and electrical conductivity, to Professor K. Rankama, Dr. M. Lehtinen and Dr. K. Kinnunen, who gave helpful comments on the original manuscript, to Mrs. Gillian Häkli, who corrected the English, to Mrs. K. Blomster and Ms. T. Koivisto, who drew the figures, and to Mrs. R. Tapanainen and Mrs. A. Romberg who typed the manuscript. 


\section{References}

Banerjee, S. K. and Hargraves, R. B., 1971. Natural remanent magnetization of carbonaceous chondrites. Earth Planet. Sci. Lett. 10, 392396.

Banerjee, S. K. and Hargraves, R. B., 1972. Natural remanent magnetizations of carbonaceous chondrites and the magnetic field in the early solar system. Earth Planet. Sci. Lett. 17, 110119.

Brecher, A. and Fuhrman, M., 1979. Magnetism, shock and metamorphism in chondritic meteorites. Phys. Earth Plan. Int. 20, 350-360.

Brecher, A. and Ranganayaki, B. P., 1975. Paleomagnetic systematics of ordinary chondrites. Earth Planet. Sci. Lett. 25, 57-67.

Brown, H. E., 1979. Conductivity and frequency effects in measurements of susceptibility. Bull. Aust. Soc. Explor. Geophys. 10, 101-103.

Butler, R. F., 1972. Natural remanent magnetization and thermomagnetic properties of the Allende meteorite. Earth Planet. Sci. Lett. 17, $120-128$.

Eskola, L., Tervo, T. and Puranen, R., 1977. Calculation of magnetostatic anomalies and demagnetization factor by means of the method of subareas. Geological Survey of Finland, Report of Investigation No 16, 20 pp.

Gorshkov, E. S., Gus'kova, E. G. and Pochtarev, V. I., 1972. Physical properties of meteorites. Mod. Geol. 3, 105-106.

Gorshkov, E. S., Gus'kova, E. G. and Pochtarev, V. I., 1975. The magnetic investigation of the Sikhote-Alin iron meteorite shower at the site of fall. Meteoritics 10, 9-19.

Gus'kova, E. G., 1965. Study of the remanent magnetization of irons and stony-iron meteorites. Geomagnetism and Aeronomy 5, $91-96$.

Gus'kova, E.G. and Pochtarev, V.I., 1967. Magnetic fields in space according to a study of the magnetic properties of meteorites. Geomagnetism and Aeronomy 7, 245-250.

Herndon, J. M. and Rowe, M. W., 1974. Magnetism in meteorites. Meteoritics 9, 289-305.

Herndon, J. M., Rowe, M. W., Larson, E. E. and Watson, D. E., 1972. Magnetism of meteorites: A review of Russian studies. Meteoritics 7, 263-284.

Herndon, J. M., Rowe, M. W., Larson, E. E. and Watson, D. E., 1976. Thermomagnetic analysis of meteorites, 3. C3 and C4 chondrites. Earth Planet. Sci. Lett. 29, 283-290.
Hey, M. H., 1966. Catalogue of meteorites, 3rd ed., British Museum, Natural History, London, $637 \mathrm{pp}$.

Hutchison, R., Bewan, A. W. R. and Hall, J. M., 1977. Appendix to the catalogue of meteorites. British Museum, Natural History, London, $297 \mathrm{pp}$.

Joseph, R. I., 1967. Ballistic demagnetizing factor in uniformly magnetized rectangular prisms. J. Appl. Phys. 38, 2405-2406.

Joseph, R. I. and Schlömann, E., 1965. Demagnetizing field in non-ellipsoidal bodies. J. Appl. Phys. 36, 1579-1593.

Knowlton, A. E., 1949. Standard handbook for electrical engineers. McGraw-Hill Book Company, New York - Toronto - London, $2311 \mathrm{pp}$.

Larson, E. E., Watson, D. E., Herndon, J. M. and

Rowe, M. W., 1974. Thermomagnetic analysis of meteorites, 1. C1 chondrites. Earth Planet. Sci. Lett. 21, 345-350.

Lovering, J. F., and Parry, L. G., 1962. Thermomagnetic analysis of coexisting nickel-iron metal phases in iron meteorites and the thermal histories of the meteorites. Geochim. Cosmochim. Acta 26, 361-382.

Lovering, J. F., Parry, L. G. and Jaeger, J. C., 1960. Temperatures and mass loss in iron meteorites during ablation in the Earth's atmosphere. Geochim. Cosmochim. Acta 19, 156-157.

McElhinny, M. W., 1973. Palaeomagnetism and plate tectonics. Cambridge Earth Science Series, Cambridge University Press, $358 \mathrm{pp}$.

Nagata, T., 1979. Meteorite magnetism and the early solar system magnetic field. Phys. Earth Planet. Int. 20, 324-341.

Neuvonen, K. J., Ohlson, B., Papunen, H., Häkli, T. A. and Ramdohr, P., 1972. The Haverö ureilite. Meteoritics 7, 515-531.

Noltimier, H. C., 1971. Magnetic rock cylinders with neglible shape anisotropy. J. Geophys. Res. 76, 4035-4037.

Osborn, J. A., 1945. Demagnetizing factors of the general ellipsoid. Phys. Rev. 67, 351-357.

Pesonen, L. J., 1973. Kirkland Lake alueen vulkaanisten kivien magneettisista ominaisuuksista ja paleomagnetismista. In Finnish with English Abstract: On the magnetic properties and paleomagnetism of the Blake River Group of Archean volcanic rocks from Kirkland Lake Area, Ontario Geologi 25, p. 91-94.

Pesonen, L. J. and Kukkonen, I. T., 1983. Physical properties of 54 meteorites. 
Report Q 16.2/1/1983, Department of Geophysics, Geological Survey of Finland, 35 pp.

Poikonen, A., 1980. Sähkönjohtavuuden vaikutus induktiivisissa suskeptibiliteettimittauksissa (in Finnish). Thesis, Helsinki University of Technology, $72 \mathrm{pp}$.

Puranen, M., 1978. Fluxgate-tyyppinen mittauslaite kivinäytteiden remanenssimagnetismin tutkimista varten/»Oerstedt-mittari». In Finnish with English summary: Fluxgate-type instrument for measurement of remanent magnetization of rock samples. Report $Q$ $16.1 / 27.2 / 78 / 1$, Department of Geophysics, Geological Survey of Finland, $11 \mathrm{pp}$.

Puranen, M. and Puranen, R., 1977. Apparatus for the measurement of magnetic susceptibility and its anisotropy. Geological Survey of Finland, Report of Investigation No. 28, 46 pp.

Sharma, P. V., 1968. Demagnetization effect of a rectangular prism. Geophysics 33, 132-134.

Sonett, C. P., 1978. Evidence for a primordial magnetic field during the meteorite parent body era. Geophys. Res. Lett. 5, 151-154.

Stacey, F. D. and Banerjee, S. K., 1974. The physical principles of rock magnetism. Elsevier, Amsterdam - London - New York, 195 pp.

Stacey, F. D. and Lovering, J. F., 1961. Thermo- magnetic properties, natural magnetic moments and magnetic anisotropies of some chondritic meteorites. J. Geophys. Res. 66, 1523-1534.

Sugiura, N., 1977. Magnetic properties and remanent magnetization of stony meteorites. J. Geomag. Geoel. 29, 519-539.

Van Schmus, W. R. and Wood, J. A., 1967. A chemical-petrologic classification for the chondritic meteorites. Geochim. Cosmochim. Acta 31, 747-765.

Wasson, J. T., 1974. Meteorites. Classification and properties. Springer-Verlag, Berlin Heidelberg - New York, 316 pp.

Watson, D. E., Larson, E. E., Herndon, J. M. and Rowe, M. W., 1975. Thermomagnetic analysis of meteorites, 2. C2 Chondrites. Earth Planet. Sci. Lett. 27, 101-107.

Weaving, B., 1962. The magnetic properties of the Brewster meteorite. Geophys. J. 7, 203211.

Wiik, H. B., 1969. On regular discontinuities in the composition of meteorites. Societas Scientiarum Fennica Commentationes Physico-Mathematicae 34, 135-145.

Manuscript received, April 15, 1983 
APPENDIX

SUMMARY OF THE PETROPHYSICAL PROPERTIES OF THE METEORITE SAMPLES INVESTIGATED

\begin{tabular}{lllllllll}
\hline Meteorite & $\begin{array}{l}\text { Sub- } \\
\text { class }\end{array}$ & $\mathrm{m}$ & $\varrho$ & $\chi$ & $\mathrm{M}$ & $\mathrm{Q}$ & $\begin{array}{c}\text { Mu- Comments } \\
\text { seum }\end{array}$ \\
\hline
\end{tabular}

\begin{tabular}{|c|c|c|c|c|c|c|c|c|}
\hline \multicolumn{9}{|c|}{ Irons } \\
\hline Bitburg & I B & 93.6 & 4.94 & 6089 & 63 & 0.03 & 1 & $1,2,7,8$ \\
\hline Coolac & I A & 153.2 & 7.68 & 3961 & 74 & 0.05 & 1 & \\
\hline Toluca & I A & 107.7 & 7.16 & 9773 & 106 & 0.03 & 2 & \\
\hline Carbo & II D & 139.8 & 7.54 & 6360 & 333 & 0.13 & 1 & 1 \\
\hline Carlton & III C & 24.8 & 7.07 & 13026 & 6329 & 1.22 & 1 & 1 \\
\hline Casas Grandes & III A & 36.3 & 7.88 & 14155 & 1423 & 0.25 & 1 & \\
\hline Grant & III B & 60.7 & 7.77 & 34176 & - & - & 1 & 8 \\
\hline Mungindi & III C & 116.2 & 7.78 & 10035 & 539 & 0.13 & 1 & 3 \\
\hline Muonionalusta & IV A & 85.3 & 7.81 & 13599 & 3414 & 0.63 & 1 & 3 \\
\hline \multicolumn{9}{|c|}{ Stony-irons } \\
\hline Estherville & Mes. & 78.2 & 5.13 & 5547 & 55 & 0.02 & 1 & 1 \\
\hline Crab Orchard & Mes. & 110.0 & 4.17 & 8968 & 2348 & 0.66 & 1 & 1 \\
\hline Morristown & Mes. & 17.7 & 4.11 & 8273 & 1056 & 0.32 & 1 & \\
\hline Brenham & Pal. & 55.6 & 5.14 & 7621 & 1112 & 0.37 & 1 & \\
\hline Eagle Station & Pal. & 5.6 & 4.66 & 2482 & 2213 & 2.24 & 1 & \\
\hline Imilac & Pal. & 41.8 & 5.21 & 9265 & 1083 & 0.29 & 1 & \\
\hline Krasnojarsk & Pal. & 76.5 & 4.93 & 7538 & 4293 & 1.43 & 1 & \\
\hline Marjalahti & Pal. & 70.0 & 6.02 & 60395 & 191 & 0.01 & 1 & 3 \\
\hline \multicolumn{9}{|c|}{ Chondrites } \\
\hline \multicolumn{9}{|c|}{ Subclass E } \\
\hline Abee & E 4 & 18.2 & 3.71 & 3731 & 1186 & 0.80 & 1 & \\
\hline Hvittis & E 6 & 21.7 & 3.61 & 3601 & 1614 & 1.13 & 1 & 3 \\
\hline \multicolumn{9}{|c|}{ Subclass H } \\
\hline Clovis & H 3 & 76.9 & 3.28 & 432 & 354423 & 2062 & 1 & 4,8 \\
\hline Bath & $\mathrm{H} 4$ & 92.5 & 3.46 & 517 & 41 & 0.20 & 1 & \\
\hline Kesen & $\mathrm{H} 4$ & 114.7 & 3.51 & 2075 & 70 & 0.08 & 1 & \\
\hline Metsäkylä & $\mathrm{H} 4$ & 31.5 & 3.31 & 533 & 121 & 0.57 & 1 & \\
\hline Metsäkylä & $\mathrm{H} 4$ & 203.1 & 3.21 & 208 & 326 & 3.94 & 3 & \\
\hline Forest City & H 5 & 149.3 & 3.44 & 1772 & 173 & 0.25 & 1 & 1 \\
\hline Hessle & H 5 & 127.8 & 3.27 & 1478 & 34 & 0.06 & 1 & 1 \\
\hline Hugoton & H 5 & 75.8 & 3.30 & 378 & 704 & 4.68 & 1 & \\
\hline Ställdalen & H 5 & 142.2 & 3.60 & 2406 & 6736 & 7.04 & 1 & 1 \\
\hline Ställdalen & H 5 & 37.3 & 3.54 & 3193 & 118 & 0.09 & 1 & 1 \\
\hline Morland & H 6 & 105.0 & 3.55 & 1934 & 708 & 0.92 & 1 & \\
\hline Chamberlin & $\mathrm{H}$ & 104.4 & 3.34 & 418 & 1882 & 11.32 & 1 & \\
\hline Vernon County & $\mathrm{H}$ & 25.8 & 3.18 & 3263 & 229 & 0.18 & 1 & \\
\hline \multicolumn{9}{|c|}{ Subclass L } \\
\hline Barratta & L 4 & 263.0 & 3.45 & 822 & 132 & 0.40 & 1 & \\
\hline Bjurböle & L 4 & 127.2 & 2.92 & 332 & 33 & 0.25 & 1 & \\
\hline Bjurböle & L 4 & 944.1 & 3.01 & 400 & 28 & 0.18 & 2 & 1 \\
\hline Bjurböle & L 4 & 53.7 & 2.91 & 317 & 139 & 1.10 & 2 & \\
\hline Bjurböle & L 4 & 48.2 & 2.86 & 429 & 128 & 0.75 & 2 & \\
\hline Bjurböle & L 4 & 44.5 & 2.85 & 344 & 11 & 0.08 & 2 & \\
\hline Bjurböle & L 4 & 128.2 & 2.89 & 395 & 8 & 0.05 & 1 & 1 \\
\hline Bjurböle & L 4 & 122.4 & 2.94 & 404 & 7 & 0.04 & 1 & \\
\hline Bjurböle & L 4 & 48.2 & 2.88 & 340 & 16 & 0.12 & 1 & 1 \\
\hline Bjurböle & L 4 & 125.4 & 2.91 & 314 & 6 & 0.05 & 1 & \\
\hline Bjurböle & L 4 & 91.4 & 2.91 & 366 & 17 & 0.12 & 1 & \\
\hline Bjurböle & L 4 & 106.3 & 2.85 & 318 & 46 & 0.36 & 1 & \\
\hline
\end{tabular}




\begin{tabular}{|c|c|c|c|c|c|c|c|c|}
\hline Bluff & L 5 & 42.4 & 3.39 & 787 & 147 & 0.47 & 1 & \\
\hline Ergheo & L 5 & 55.0 & 3.31 & 772 & 141 & 0.46 & 1 & \\
\hline Alfianello & L 6 & 50.9 & 3.26 & 777 & 31 & 0.10 & 1 & 1 \\
\hline Bruderheim & L 6 & 78.8 & 3.36 & 793 & 37 & 0.12 & 1 & 1 \\
\hline Buschhof & L 6 & 35.8 & 3.22 & 638 & 13 & 0.05 & 1 & \\
\hline Holbrook & L 6 & 40.0 & 3.17 & 480 & 43 & 0.23 & 2 & 1 \\
\hline Valkeala & L 6 & 135.6 & 3.34 & 285 & 362 & 3.19 & 1 & 3 \\
\hline Salla & $\mathrm{L}$ & 95.2 & 3.39 & 370 & 576 & 3.92 & 1 & 3 \\
\hline Salla & $\mathrm{L}$ & 462.1 & 3.39 & 622 & 505 & 2.04 & 3 & \\
\hline St. Michel & $\mathrm{L}$ & 20.4 & 3.39 & 612 & 88 & 0.36 & 1 & 3 \\
\hline \multicolumn{9}{|c|}{ Subclass LL } \\
\hline Soko-Banja & LL 4 & 2.78 & 3.45 & 128 & 5 & 0.10 & 1 & 5,10 \\
\hline Soko-Banja & LL 4 & 2.42 & 3.45 & 178 & 8 & 0.11 & 1 & 5,10 \\
\hline Ensisheim & LL 6 & 4.52 & 3.45 & 650 & 5 & 0.02 & 1 & 5,10 \\
\hline Dhurmsala & LL 6 & 75.2 & 3.29 & 157 & 6 & 0.10 & 1 & \\
\hline Dhurmsala & LL 6 & 55.1 & 3.33 & 158 & 2 & 0.03 & 1 & \\
\hline Manbhoom & LL 6 & 1.17 & 3.45 & 24 & 19 & 1.99 & 1 & 5,10 \\
\hline \multicolumn{9}{|c|}{ Subclass C } \\
\hline Ornans & $\mathrm{CO} 3$ & 4.9 & 3.45 & 180 & 2 & 0.03 & 1 & 5,10 \\
\hline Ornans & $\mathrm{CO} 3$ & 3.8 & 3.45 & 280 & 33 & 0.30 & 1 & 5,10 \\
\hline Orgueil & CI 1 & 5.8 & 2.25 & 591 & 13 & 0.06 & 1 & $1(?), 5,10$ \\
\hline Orgueil & CI 1 & 3.6 & 2.25 & 583 & 45 & 0.19 & 1 & $1(?), 5,10$ \\
\hline Orgueil & CI 1 & 1.5 & 2.25 & 614 & 12 & 0.05 & 1 & $1(?), 5,10$ \\
\hline Orgueil & CI 1 & 0.7 & 2.25 & - & 292 & - & 1 & $6,8,10$ \\
\hline \multicolumn{9}{|c|}{ Achondrites } \\
\hline Norton County & Aubr. & 245.1 & 3.05 & 40 & 6 & 0.38 & 1 & \\
\hline Norton County & Aubr. & 47.9 & 2.88 & 95 & 2 & 0.05 & 3 & \\
\hline Johnstown & Diog. & 89.8 & 3.14 & 46 & 4 & 0.23 & 1 & 1 \\
\hline Juvinas & Eucr. & 26.8 & 2.88 & 7 & 4 & 1.44 & 1 & 1 \\
\hline Sioux County & Eucr. & 35.7 & 2.74 & 8 & 4 & 1.26 & 1 & \\
\hline Stannern & Eucr. & 26.9 & 2.99 & 4 & 5 & 3.14 & 1 & 1 \\
\hline Haverö & Ureil. & 0.7 & 3.29 & 1222 & 2996 & 6.16 & 4 & 5,9 \\
\hline Haverö & Ureil. & 0.2 & 3.29 & 1283 & 1007 & 1.97 & 4 & 5,9 \\
\hline Novo Urei & Ureil. & 6.76 & 3.3 & 614 & 9 & 0.04 & 1 & 5,10 \\
\hline
\end{tabular}

Meteorite name is given according to Hey (1966) and Hutchison et al. (1977)

Subclass according to Wasson (1974)

m mass of sample $\left(10^{-3} \mathrm{~kg}\right)$

e bulk density $\left(10^{3} \mathrm{kgm}^{-3}\right)$

$\chi \quad$ low field mass susceptibility (SI) $\left(10^{-7} \mathrm{~m}^{3} \mathrm{~kg}^{-1}\right)$

$\mathrm{M}$

Q

Museum or

collection

natural remanent magnetization (NRM) $\left(10^{-5} \mathrm{Am}^{2} \mathrm{~kg}^{-1}\right)$

Koenigs berger ratio (dimensionless)

$1=$ Meteorite collection, Department of Geology, University of Helsinki

$2=$ Meteorite collection, Department of Mining and Metallurgy, Helsinki

University of Technology

$3=$ Meteorite collection, Geological Survey of Finland

$4=$ Lauri J. Pesonen meteorite collection

Comments $\quad 1=$ Fusion crust present

$2=$ Possibly smelted in a furnace according to Hey (1966)!

$3=$ The sample was in the storage test. $\mathrm{M}$ is an arithmetic mean of storage test values

4 = Extremely high value of M, perhaps caused by hand magnet contamination

$5=\chi$ and $\mathrm{M}$ were calculated by using an estimated value of volume

$6=\mathrm{M}$ was measured with a spinner magnetometer

$7=$ Not included in Table 1

$8=$ Not included in Figure 4

$9=$ Density adopted from Neuvonen et al. (1972)

$10=$ Density adopted from Wasson (1974, Table XVII-1) 